\title{
Effect of point 6 acupressure on chemotherapy associated nausea and vomiting among adolescents with cancer
}

\author{
Fawzia El Sayed Abusaad ${ }^{* 1}$, Wafaa G.M. Ali² \\ ${ }^{1}$ Pediatric nursing department, Mansoura University, Mansoura, Egypt \\ ${ }^{2}$ Medical surgical nursing department, Mansoura University, Mansoura, Egypt
}

Received: November 15, 2015

DOI: $10.5430 /$ jnep.v6n4p122
Accepted: December 16, 2015 Online Published: December 27, 2015

URL: http://dx.doi.org/10.5430/jnep.v6n4p122

\begin{abstract}
Background: Despite the development of effective antiemetic drugs, nausea and vomiting continue to be the primaryside effects associated with the usage of chemotherapy among adolescent with cancer. The aim of this study was to examine the effect of using acupressure Point 6 (P6) on reducing nausea and vomiting in cancer adolescents undergoing chemotherapy.

Methods: A quasi experimental study was conducted at pediatric inpatients and outpatient departments of Mansoura oncology center. 60 cancer adolescents receiving chemotherapy was selected using a convenience sample and divided equally into experimental group who receive antiemetic plus an acupressure P6 intervention and control group who receive antiemetic only. The tool designed for the study comprised of: sciodemographical data and clinical data from medical record. Rhodes Index of Nausea and Vomiting scale was used to measure the severity, frequency and duration of nausea, vomiting and retching.

Results: There was a decrease in the total mean score of nausea, vomiting and retching in study group compared to control group with a statistical significant difference between both group regarding its frequency, severity and duration. Also more than one third of the study group (40\%) view that acupressure P6 is moderately effective, $33.3 \%$ of them show it effective in using while only $26.7 \%$ stated that it is slightly effective.

Conclusions: The results of this study showed that acupressure has a significant role in the reduction of nausea, vomiting and retching associated with chemotherapy among adolescents with cancer, and use of this non-pharmacologic technique for oncology nurses is suggested.
\end{abstract}

Key Words: Acupressure, Nausea, Vomiting, Adolescents with cancer, Chemotherapy

\section{INTRODUCTION}

World Health Organization (WHO) defined cancer as a chronic health problem like hypertension and diabetes that increasing rapidly in incidence all over the world. It is predicted to be a worldwide critical cause of morbidity and mortality in the next few decades. By year 2020 in the world approximately 24.6 million of people will live with cancer with about $12.5 \%$ of all deaths attributable to cancer. ${ }^{[1]}$ Cancer is a class of disease in which group of cells show out of control growth, invasions and sometime metastasis to different parts of the body. ${ }^{[2]}$ Chemotherapeutic agents are the preference drug typically cytotoxic in nature, which can destroy most of cancer cells. Chemotherapy works by preventing or slowing the increase of cancer cells which develop

${ }^{*}$ Correspondence: Fawzia El Sayed Abusaad; Email: fawziaabusaad2013@gmail.com; Address: Pediatric nursing department, Mansoura University, Mansoura, Egypt. 
and divide quickly. ${ }^{[3]}$ Nausea and vomiting are among the most distressing and debilitating adverse effects identified by patients receiving chemotherapy treatment. ${ }^{[4]}$

Although the recent advances in pharmaceutical technologies, over $40 \%$ of adolescents with cancer who receive chemotherapy with antiemetic medications still suffer nausea and vomiting and as many as $20 \%$ of patients refuse to continue chemotherapy because of severe nausea and vomiting. ${ }^{[5]}$ Insufficient management of these specific side effects results in metabolic imbalance, fatigue, distress, and poor quality of life. ${ }^{[6,7]}$ More efficient antiemetic drugs will absolute confidence be evolved constantly and this figure will change in the future. Patients especially adolescents may be reluctant to report side effects of chemotherapy because they expect and accept these effects. ${ }^{[8]}$ Nurses should observe patient carefully for chemotherapy induced nausea and vomiting and help them to discover strategies for managing these effects. ${ }^{[9]}$

Efforts have been made by investigators to find nonpharmacological strategies as alternatives to antiemetic drugs. ${ }^{[10]}$ Research studies discovered that acupressure may hold the solution to the most prevalent chemotherapy induced side effects as it succeeded in preventing vomiting in about $66 \%$ of cancer adolescents. ${ }^{[1,11,12]}$ Acupressure is an ancient healing art that is based on the traditional Chinese medicine practice of acupuncture technique to balance energy channels in the body. Finger pressure is used to stimulate trigger points of energy or cosmic life force on the body which is called acu-points. ${ }^{[13]}$ Pressing these points can help release muscle tension and promote blood circulation.

Researches emphasize that acupressure is one of the wellinvestigated non-pharmacological methods for reducing the incidence of nausea and vomiting throughout making pressure with fingers or bands on the body's acu-points that is easy to perform, painless, inexpensive, and an effective approach. The Point 6 (P6) point is located on the anterior surface of the forearm, 3-finger widths up from the first wrist crease and between the tendons of flexor carpiradialis and Palmaris longus. ${ }^{[14]}$ Oncology nurses can play an essential role in reducing the load of chemotherapy associated adverse effects. They usually the most common point of contact for adolescents with cancer. ${ }^{[15]}$ More accurate assessment using effective communication technique with adolescents and their families taking into consideration their differences in educational level, age, cultural background and experience before and during chemotherapy will ensure that appropriate antiemetic therapy is received, improve their adherence to acupressure and consequently better outcomes. ${ }^{[16]}$

Practice of acupressure requires some training and experience; however, the technique is widely accessible to health- care professionals, particularly clinical nurses. This technique should be tried not only by healthcare professionals but also by family members or patient themselves. ${ }^{[17]}$ However, a few studies on the efficacy of acupressure for controlling chemotherapy induced nausea and vomiting are available. This study aims to examine the effectiveness of applying point 6 acupressure on reducing nausea and vomiting induced by chemotherapy among cancer adolescents at Mansoura oncology center.

\section{Research hypothesis}

Cancer adolescents undergoing chemotherapy using acupressure with standard antiemetic will experience less nausea, retching, and vomiting in terms of frequency, severity and distress than adolescents receiving standard antiemetic only.

\section{SUBJECTS AND METHODS}

\subsection{Design}

A quasi experimental design, pre and post intervention was used.

\subsection{Setting}

This study was conducted at pediatric inpatients and outpatients departments of Mansoura oncology center. This hospital belongs to Mansoura University Medical centers and receives children who are suffering from all types of cancer from all Dakahlia Governorate and other near governorate.

\subsection{Subjects}

A convenience sample (all target subject fulfilling the inclusion criteria and willing to participate in the study) of sixty cancer adolescents receiving chemotherapy was selected and divided randomly by using simple random sampling technique into two equal groups, experimental group who receiving antiemetic with P6 acupressure intervention and control group who receiving antiemetic only. Inclusion criteria included age from 11-17 years, both sexes, suffer from chemotherapy induced nausea and vomiting, receivedprescribed antiemetic before chemotherapy, no prior experience with acupressure and willing to participate in the study. The researchers excluded adolescents if they received palliative chemotherapy, had metastatic disease, suffered from gastro intestinal tract cancer, and had lymphoedema of the arms.

\subsection{Tools of data collection}

Data were collected using a questionnaire comprised of four parts:

Part (1) concerned with demographical data of the participant such as age, gender, educational level and residence.

Part (2) concerned with clinical data that obtained from the 
adolescent medical record, including cancer diagnosis, its grade, and antiemetic ordered.

Part (3) Rhodes Index of Nausea and Vomiting scale, which designed to measure the severity, frequency and distress of nausea and vomiting. It is an eight-item instrument that uses a five-point Likert scale giving a total of 32 grade. ${ }^{[18]}$ The scoring of its items ranged from (0) for the least amount of distress to (4) for the most distress.The English versions of this instrument were translated into Arabic and backtranslated into English to ensure equivalency. Validity of the Arabic version was tested through make a jury for both English and Arabic version for matching by introducing them for five nursing expertise. Reliability of our translated version tested by test retest reliability testing on ten patients and Pearson correlation was 0.82 .

Part (4) concerned with additional question asking about the effectiveness of acupressure from the patient's point of view, it's a Likert scale include five responses ranging from $(0)$ for not effective to (5) for very effective. ${ }^{[19]}$

\subsection{Procedure}

- In planning phase: Adolescents who met the inclusion criteria were determined then each adolescent and his/her parent were informed about the purpose and duration of the study. Adolescents and their parents' verbal consent to participate in the study were obtained after ensuring the confidentiality, privacy and their rights to withdraw from the study at any time. In addition, permission to conduct the study was obtained from the administrative board of the Mansoura Oncology Center.

- Each adolescent in both groups submitted to the protocol of chemotherapy throughout 4 weeks in which adolescents received chemotherapy dose/week, beside antiemetic drug.

- Acupressure teaching handout was developed by the researchers and video was used to teach adolescents and their parent's acupressure techniques. Validity of the content has been established by three specialists of pediatric medicine and nursing staff.

- In implementation phase both groups received prescribed antiemesis medication; however, the intervention group received P6 acupressure training, they was educated to perform the finger acupressure maneuver for 5 minutes on P6 point located at 3-finger widths up from the first palmar crease, between Palmaris longus and flexor carpiradialis tendons point.

- Instruction session done by the researchers on indi- vidualized basis through demonstration by researchers and redemonstration by adolescent and his/her family member. In addition pre-prepared video and handout provided for the study group.

- Study group participants instructed to perform P6 point acupressure at least 3 times a day; before starting chemotherapy and mealtimes or anytime sensations of nausea were felt.

- Evaluating phase: The standardized, Rhodes Index of Nausea and Vomiting scale was used to assess the nausea, retching, and vomiting in both groups throughout four weeks.

- At the first meeting with participants, all demographic and clinical data about the participants were collected. Adolescents in both groups were instructed to complete a daily dairy of rhodes index of nausea and vomiting scale twice a day, at morning and evening.

- The mean scores of morning and evening readings of rhodes index for each participant was used in comparing between study and control group.

\subsection{Statistical analysis}

Data were analyzed using Statistical Package for the Social Sciences (SPSS) Version 20.0; Qualitative variables were presented as number and percentage. Quantitative variables were presented as mean $\pm \mathrm{SD}$. To check the difference between two groups independent $t$-test was used. $p \leq .05$ was considered statistically significant.

\section{RESULT}

Table 1 shows that each group consisted of 30 adolescents undergoing chemotherapy, their age were between 11-17 years with the mean age of $13.23 \pm 1.72$ years in the study group and $12.98 \pm 1.83$ years in the control group. Three quarters of the participants in both group $70 \%$ and $66.3 \%$ respectively were male and were from rural areas $73.4 \%$ and $60 \%$ respectively. Regarding their level of education $53.3 \%$ in the study group and $40 \%$ in the control group were in preparatory school. Most of adolescents had leukemia $56.6 \%$ in the study group and $40 \%$ in the control group. All participants were used Zofran as antiemetic.

Table 2 shows that the mean score of vomiting, nausea and retching frequency, severity and distress in study group using acupressure were decreased except frequency of vomiting was statistically higher in study compared to control group in the first week of administrating chemotherapy with a statistical significant differences between both group regarding vomiting frequency $p=.001$ and retching frequency $p=.002$. 
Table 1. Demographic and medical Characteristics' of the study participants

\begin{tabular}{|c|c|c|c|}
\hline Items & Study group $(n=30)$ & Control group $(n=30)$ & Significance test \\
\hline Age (year) $\mathrm{M} \pm \mathrm{SD}$ & $13.23 \pm 1.72$ & $12.98 \pm 1.83$ & $t=1.517 p=.135$ \\
\hline $\begin{array}{l}\text { Sex } \\
\text { Male } \\
\text { Female }\end{array}$ & $\begin{array}{l}21(70 \%) \\
9(30 \%)\end{array}$ & $\begin{array}{l}20(66.6 \%) \\
10(33.4 \%)\end{array}$ & $\begin{array}{l}\chi^{2}=2.71 \\
p=.795\end{array}$ \\
\hline $\begin{array}{l}\text { Residence } \\
\text { Urban } \\
\text { Rural }\end{array}$ & $\begin{array}{l}8(26.7 \%) \\
22(73.4 \%)\end{array}$ & $\begin{array}{l}12(40 \%) \\
18(60 \%)\end{array}$ & $\begin{array}{l}\chi^{2}=4.022 \\
p=.045\end{array}$ \\
\hline $\begin{array}{l}\text { Educational Level } \\
\text { Primary school } \\
\text { Preparatory school } \\
\text { Secondary school }\end{array}$ & $\begin{array}{l}8(26.7 \%) \\
16(53.3 \%) \\
6(20 \%)\end{array}$ & $\begin{array}{l}10(33.4 \%) \\
12(40 \%) \\
8(26.6 \%)\end{array}$ & $\begin{array}{l}\chi^{2}=1.201 \\
p=.548\end{array}$ \\
\hline $\begin{array}{l}\text { Cancer Diagnosis } \\
\text { Leukemia } \\
\text { Hodgkin disease } \\
\text { Neuroblastoma }\end{array}$ & $\begin{array}{l}17(56.6 \%) \\
6(20 \%) \\
7(23.4 \%)\end{array}$ & $\begin{array}{l}12(40 \%) \\
10(33.3 \%) \\
8(26.7 \%)\end{array}$ & $\begin{array}{l}\chi^{2}=3.892 \\
p=.273\end{array}$ \\
\hline $\begin{array}{l}\text { Cancer Stages } \\
\text { Stage } 1 \\
\text { Stage } 2 \\
\text { Stage } 3\end{array}$ & $\begin{array}{l}16(53.4 \%) \\
10(33.3 \%) \\
4(13.3 \%)\end{array}$ & $\begin{array}{l}14(46.6 \%) \\
13(43.4 \%) \\
3(10 \%)\end{array}$ & $\begin{array}{l}\chi^{2}=1.143 \\
p=.565\end{array}$ \\
\hline
\end{tabular}

Table 2. Comparing chemotherapy induced nausea and vomiting among study and control group in the first week

\begin{tabular}{lllll}
\hline Items & Study group $(\mathbf{M} \pm \mathbf{S D})$ & Control group $(\mathbf{M} \pm \mathbf{S D})$ & $\boldsymbol{t}$-test & $\boldsymbol{p}$-value \\
\hline Vomiting frequency & $2.66 \pm 1.21$ & $2.13 \pm .681$ & 1.83 & .001 \\
Retching experience & $1.86 \pm 1.07$ & $2.50 \pm .820$ & 2.56 & .567 \\
Vomiting distress & $2.24 \pm .935$ & $2.53 \pm .776$ & 1.35 & .769 \\
Nausea duration & $1.96 \pm .718$ & $2.34 \pm .606$ & 2.13 & .240 \\
Nausea severity & $1.83 \pm .698$ & $2.40 \pm .498$ & 3.61 & .889 \\
Vomiting severity & $2.10 \pm .959$ & $2.86 \pm .628$ & 3.66 & .515 \\
Nausea frequency & $2.10 \pm 1.02$ & $2.56 \pm .727$ & 2.02 & .955 \\
Retching frequency & $1.56 \pm .626$ & $2.03 \pm .490$ & 3.21 & .002 \\
\hline
\end{tabular}

It is clear from Table 3 that there was an obvious decrease in pared to control group in relation to vomiting frequency $p$ the mean score of chemotherapy induced nausea and vom- $=.001$, nausea duration $p=.009$, and nausea frequency $p=$ iting in study and control group with a highly statistical .002 . significant difference in group using acupressure P6 com-

Table 3. Comparing chemotherapy induced nausea and vomiting among study and control group in the second week

\begin{tabular}{lllll}
\hline Items & Study group $(\mathbf{M} \pm \mathbf{S D})$ & Control group $(\mathbf{M} \pm \mathbf{S D})$ & $\boldsymbol{t}$-test & $\boldsymbol{p}$-value \\
\hline Vomiting frequency & $1.83 \pm .949$ & $2.20 \pm .406$ & 1.94 & .001 \\
Retching experience & $1.80 \pm .664$ & $2.00 \pm .454$ & -.430 & .031 \\
Vomiting distress & $1.90 \pm .661$ & $1.83 \pm .530$ & 4.97 & .783 \\
Nausea duration & $1.56 \pm .626$ & $2.26 \pm .449$ & 3.20 & .794 \\
Nausea severity & $1.73 \pm .583$ & $2.23 \pm .626$ & 5.17 & .050 \\
Vomiting severity & $1.63 \pm .850$ & $2.25 \pm .504$ & .192 & .002 \\
Nausea frequency & $1.76 \pm .858$ & $1.80 \pm .406$ & 2.93 & .042 \\
Retching frequency & $1.26 \pm .449$ & $1.76 \pm .817$ & & \\
\hline
\end{tabular}


Table 4 represents a continuous decrease in the mean score of chemotherapy induced nausea and vomiting in both groups with a highly statistical significant difference in study group comparing to control group regarding to nausea severity $p=$ .000 , and retching frequency $p=.000$.

Table 5 shows a continuous lowering in the mean score nausea, vomiting and retching severity, frequency and distress with no significant difference regarding chemotherapy induced nausea and vomiting except vomiting distress $p=.01$, nausea severity $p=.06$, nausea frequency $p=.02$ and retching frequency $p=.04$, there was significant improvement in study group compared to control group.

Figure 1 shows significant reduction in the total mean score of chemotherapy induced nausea and vomiting in study group compared to control group with a statistical difference between both group in relation to nausea duration, nausea frequency and retching frequency $p=.013, .056$ and .001 respectively.

Table 4. Comparing chemotherapy induced nausea and vomiting among study and control group in the third week

\begin{tabular}{|c|c|c|c|c|}
\hline Items & Study group $(\mathrm{M} \pm \mathrm{SD})$ & Control group (M \pm SD) & $t$-test & $p$-value \\
\hline Vomiting frequency & $1.23 \pm .626$ & $1.90 \pm .305$ & 5.24 & .024 \\
\hline Retching experience & $1.26 \pm .639$ & $1.70 \pm .466$ & 2.99 & .266 \\
\hline Vomiting distress & $1.43 \pm .773$ & $1.30 \pm .466$ & -.808 & .047 \\
\hline Nausea duration & $1.16 \pm .698$ & $1.76 \pm .568$ & 3.64 & .321 \\
\hline Nausea severity & $1.33 \pm .479$ & $1.90 \pm .305$ & 5.46 & .000 \\
\hline Vomiting severity & $1.30 \pm .836$ & $2.23 \pm .817$ & 4.37 & .404 \\
\hline Nausea frequency & $1.36 \pm .808$ & $1.90 \pm .542$ & 2.99 & .073 \\
\hline Retching frequency & $0.833 \pm .379$ & $1.30 \pm .836$ & 2.78 & .000 \\
\hline
\end{tabular}

Table 5. Comparing chemotherapy induced nausea and vomiting among study and control group in the fourth week

\begin{tabular}{|c|c|c|c|c|}
\hline Items & Study group $(\mathrm{M} \pm \mathrm{SD})$ & Control group (M $\pm \mathrm{SD})$ & $t$-test & $p$-value \\
\hline Vomiting frequency & $.600 \pm .968$ & $1.64 \pm .507$ & 4.34 & .060 \\
\hline Retching experience & $.566 \pm .626$ & $1.86 \pm .628$ & 8.02 & .242 \\
\hline Vomiting distress & $.700 \pm .702$ & $1.70 \pm .466$ & 6.49 & .010 \\
\hline Nausea duration & $.566 \pm .773$ & $1.60 \pm .621$ & 5.70 & .356 \\
\hline Nausea severity & $.666 \pm .606$ & $2.30 \pm .466$ & 11.69 & .064 \\
\hline Vomiting severity & $.466 \pm .819$ & $1.76 \pm .626$ & 6.90 & .507 \\
\hline Nausea frequency & $.633 \pm .614$ & $1.26 \pm .449$ & 4.55 & .012 \\
\hline Retching frequency & $.533 \pm .507$ & $.900 \pm .803$ & 2.11 & .049 \\
\hline
\end{tabular}

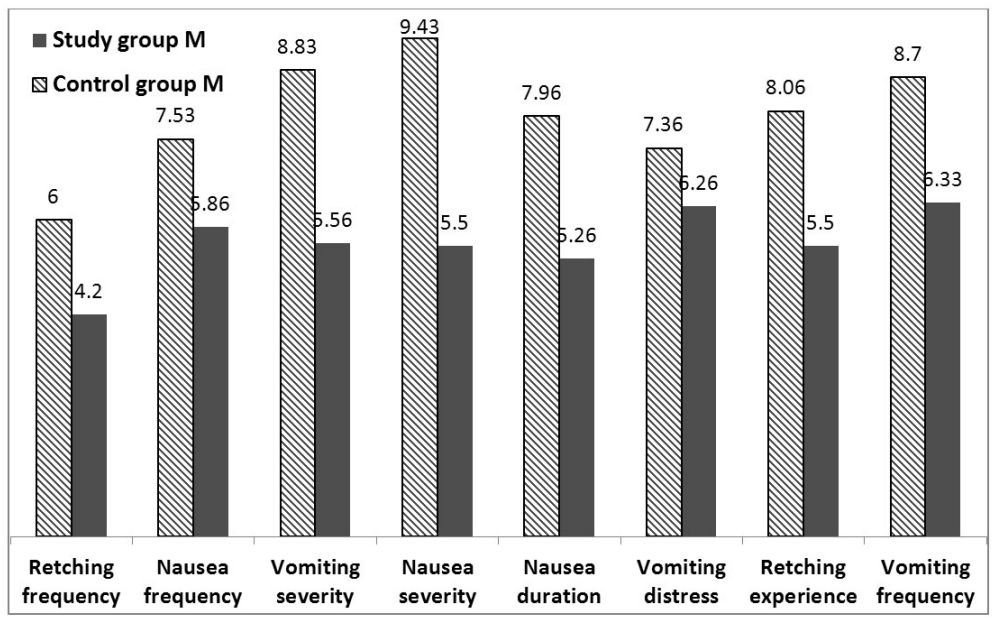

Figure 1. Comparing total Mean of chemotherapy induced nausea and vomiting among study and control groups 
Figure 2 represents participants in study group point of view regarding the effectiveness of using acupressure. More than one third of the group (40\%) view that it is moderately effective, $33.3 \%$ of them show effective using while only $26.7 \%$ stated that it is slightly effective.

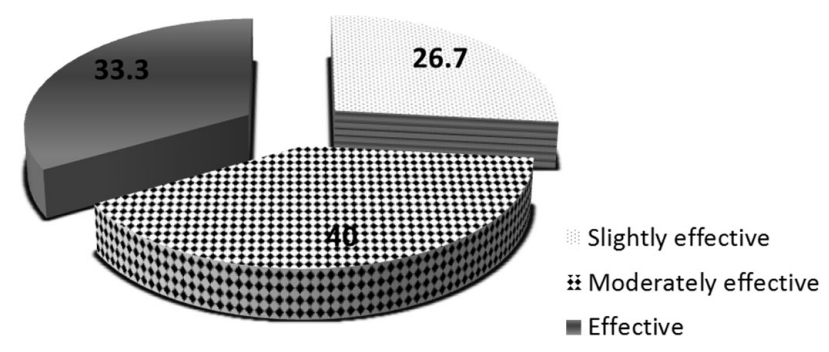

Figure 2. Effectiveness of acupressure from the patients' point of view

\section{Discussion}

Chemotherapy-induced nausea and vomiting considered as difficult symptoms to manage in clinical practice. As standard antiemetic drugs do not fully eliminate these symptoms, it is important to explore the adjuvant role of non-pharmacological and complementary therapies with antiemetic management approaches. Acupressure is one such treatment showing highly suggestive evidence so far of a positive effect in adult and pediatric oncology. ${ }^{[20]} \mathrm{Sev}-$ eral studies have shown that use of acupressure in adult patients with cancer resulted in significant improvement in chemotherapy-induced nausea and vomiting. ${ }^{[21-23]}$

The current study indicated that most of cancer adolescents receiving chemotherapyin both group were male, this result is supported by another study carried out by Anthony et al. ${ }^{[24]}$ who reported in their studies that more than two thirds of cancer adolescents who admitted to hospital for chemotherapy ware mainly male. As regard residence, most of cancer adolescents in this study were from rural areas, this may be due to lack of such specific medical services in rural areas and the fact that data collected from centers belongs to Mansoura university where treatment given free that is suitable to the socioeconomic state for majority of rural families. These results contradicted with Zwaanswijk et $a l{ }^{[16]}$ who stated that cancer are more common in those who live in urban and industrialized areas. Around half of the studied cancer adolescents were diagnosed with leukemia, this is corresponding with Newton et al. and Hasanen ${ }^{[2,3]}$ who indicated that about $30 \%$ of cancer in adolescents are leukemia and the most common form of leukemia among adolescents under 19 years is acute lymphoblastic leukemia which affects males more than females. Also statistical data from El-Mansoura oncology centers stated that the number

Published by Sciedu Press of cases of leukemia increased from 481 cases at 2011 to 541 cases during the year 2012 .

The result of the current study approved the previous stated hypothesis. It was shown that there is a reduction in chemotherapy-induced nausea and vomiting from the first week of intervention except vomiting frequency in study group was significantly higher compared to control group, this may be due to fear and stressors associated with using new technique beside the effect of chemotherapeutic drugs given for adolescents with progressive stage of cancer diagnosis. These results contradicted with Augusto et al. ${ }^{[25]}$ who mentioned that occurrence of nausea and vomiting were significantly lower in the experimental group who applied acupressure technique compared to the control group. As well as Abd El-Moneem ${ }^{[26]}$ reported in his study that acupressure (P6) proved its effectiveness in reducing frequency, amount and severity of chemotherapy-induced nausea and vomiting.

The present study indicated a significant statistical reduction in nausea,vomiting and retching frequency, its duration and severity from the second to fourth week of chemotherapy cycle among study group than control group. However there was a reduction in the mean score of chemotherapy induced nausea and vomiting in the control group but not like study group, this may be due to the adjustment of study group in applying acupressure before eating time and its relaxation effects. The findings from study done by Taspinar et al. ${ }^{[27]}$ matched with the present study as they reported that the acupressure applied to P6 was an effective maneuver in reducing chemotherapy-related nausea and may decrease the antiemetic use after chemotherapy. Also our findings is contradicted with a study done by Wulffa et al. ${ }^{[28]}$ as they found that no significant benefit was detected for adolescents receiving acupressure in their study.

Acupressure seems to be a good way to be used beside antiemetic pharmacotherapy, as it is safe, convenient and with no costs involved that make it is a cost-effective intervention. The current study found that the total mean score of acupressure group was decreased which explained study group experienced less nausea and vomiting in frequency, severity, and duration compared to control group, however adolescents in the present study feel nausea and vomit after finishing dose of chemotherapy medication than throughout receiving it. This result in congruence with what reported by Augusto et al. ${ }^{[25]}$ who observed that adolescents who received chemotherapy treatment started to have vomiting after two hours from finishing the infusion of chemotherapy despite receiving antiemetic medication. Furthermore, another study ${ }^{[29]}$ came in agreement with the result of the present 
study as they found that the need for antiemetic medication was significantly decreased in acupressure group compared to control group and episodes of vomiting were significantly reduced among patients using acupressure.

The current findings indicated that P6 acupressure applied to study group was being moderately effective in reducing chemotherapy induced nausea and vomiting in adolescent cancer patients from their point of view. This may be due to dealing with different cancer diagnosis with different stages not centered to certain disease or stages in which the progress of cancer sometimes be worth and complicated. These results supported with Qi et al. ${ }^{[13]}$ who stated that acupressure was effective in preventing nausea and vomiting among cancer adolescents. As well as Özkan et al. ${ }^{[30]}$ stated in his study that cancer adolescents used acupressure experience a higher levels of alertness during sessions of chemotherapy, reduced nausea and vomiting and no adverse effects were noted. However, another study done by Genc et al. ${ }^{[31]}$ stated that acupressure applied to P6 point decreased patients' nausea occurrence, experience and the overall experience and occurrence of nausea, vomiting, and retching combined with no effect on the occurrence or experience of vomiting or retching.

\section{CONClusion}

A significant reduction in the mean score nausea, vomiting and retching frequency, duration and severity was observed from the second to fourth week of chemotherapy cycle in study group using acupressure p6 than control group. Using acupressure P6 to study group was associated with moderate effectiveness from their point of view in reducing chemotherapy induced nausea and vomiting in pediatric cancer patients.

\section{Recommendation}

- Acupressure should be carried out as supportive nursing intervention strategies to relieve chemotherapy induced nausea and vomiting in pediatric cancer patients.

- Further study of acupressure as a complementary therapy for chemotherapy-induced nausea should be carried out in a large number of cases with a randomized control design.

- Nurse educators and clinical nurses should recognize information on non-pharmacologic management of nausea and vomiting, such as acupressure techniques and need to develop educational tools for training nursing students, patients, and families on the use of acupressure techniques.

- Further studies should be expanded to address research questions, such as whether the anticipatory psychological stress could be controlled by acupressure techniques.

- Handouts about acupressure for the management of nausea and vomiting could be available in chemotherapy units for adolescents and their families who are interested to use such technique with a given instruction from nurses or other health professionals.

\section{CONFlicts OF INTEREST Disclosure}

The authors declare that there is no conflict of interest.

\section{REFERENCES}

[1] Yeh CH, Chin LC, Chiang YC, et al. Reduction in nausea and vomiting in adolescents undergoing cancer chemotherapy by either appropriate or sham auricular acupuncture points with standard care. The Journal of Alternative and Complementary Medicine. 2012; 18(4): 334-40. PMid:22515794 http://dx.doi.org/10.1089/a cm. 2011.0102

[2] Newton S, Hickey M, Marrs J. Oncology nursing advisore. Ohio: Mosby Elsevier Co; 2009. 100 p.

[3] Hasanen AE. Side-Effect management technique for leukemic adolescents undergoing chemotherapy. Unpublished Thesis for Doctorate degree. Faculty of Nursing Mansoura University. 2014.

[4] Lebaron S, Zeltzer LK, Lebaron C, et al. Chemotherapy side effects in pediatric oncology patients: Drugs, age, and sex as risk factors. Medical and Pediatric Oncology. 2008; 16(4): 263-268. http://dx.doi.org/10.1002/mpo. 2950160408

[5] Hussein HA, Abdel Sadek BR. Acupressure for chemotherapy induced vomiting among school age adolescents. World Journal of Medical Sciences. 2013; 8(4): 373-81.
[6] Kim TI, Shin YH, Oh MS. Effect of acupressure on nausea-vomiting and weight change among pediatric cancer patients receiving anticancer chemotherapy. KJCHN. 2009; 10(1): 98-107.

[7] Pirri C, Katris P, Trotter J, et al. Risk factors at pretreatment predicting treatment-induced nausea and vomiting in Australian cancer patients: a prospective, longitudinal, observational study. Supportive Care in Cancer. 2011; 19: 1549-1563. PMid:20811914 http://dx.doi.org/10.1007/s00520-010-0982-y

[8] Darcy L, Knutsson S, Huus K, et al. The everyday life of the young child shortly after receiving a cancer diagnosis, from both adolescents's and parent's perspectives. Cancer Nurs. 2014 Nov-Dec; 37: 445-456. PMid:24406380 http://dx . doi .org/10.1097/NCC . 0 000000000000114

[9] Zander M, Hutton A, King L. Coping and resilience factors in pediatric oncology nurses. Journal of Pediatric Oncology Nursing. 2010; 27: 94-108. PMid:20044588 http://dx.doi.org/10.1177/104 3454209350154

[10] Bishop FL, Prescott P, Chan YK, et al. Prevalence of complementary medicine use in pediatric cancer: A systematic review. Pediatrics. 
2010; 125: 768-776. PMid:20308209 http://dx.doi.org/10.15 42/peds. 2009-1775

[11] Reindl TK, Geilen W, Hartmann R, et al. Acupuncture against chemotherapy-induced nausea and vomiting in pediatric oncology. Support Care Cancer. 2010; 14 (5): 172-176.

[12] Genç A, Can G, Aydiner A. The efficiency of the acupressure in prevention of the chemotherapy-induced nausea and vomiting. Supportive Care in Cancer. 2012; 21: 253-261. PMid:22678407 http://dx.doi.org/10.1007/s00520-012-1519-3

[13] Qi F, Zhao L, Zhou A, et al. The advantages of using traditional Chinese medicine as an adjunctive therapy in the whole course of cancer treatment instead of only terminal stage of cancer. Bioscience Trends. 2015; 9(1): 16-34. PMid:25787906 http://dx.doi.org $/ 10.5582 /$ bst. 2015.01019

[14] Lee J, Dodd M, Dibble S, et al. Review of acupressure studies for chemotherapy-induced nausea and vomiting control. J Pain Symptom Manage. 2010; 36(5): 29-544.

[15] Follin S, Mills EJ, Mundenm JA. Nursing process approach to excellent care. 4th ed. Philadelphia: Lippincott Co; 2006. 395-6 p. PMid:16522695

[16] Zwaanswijk M, Tates K, Dulmen SV, et al. Communicating with child patients in pediatric oncology consultations: A vignette study on child patients', parents', and survivors' communication preferences. Psycho-Oncology. 2010; 20: 269-277. PMid:20336644 http://dx.doi.org/10.1002/pon.1721

[17] Silva DRF, dos Reis PED, Gomes IP, et al. Non pharmacological interventions for chemotherapy induced nausea and vomits: Integrative review. Online Brazilian Journal of Nursing. 2009; 8(1).

[18] Rhodes VA, McDaniel RW, Homan SS, et al. An instrument to measure symptom experience. Symptom occurrence and symptom distress. Cancer Nurs. 2000; 23: 49-54. http://dx. doi.org/10.10 97/00002820-200002000-00008

[19] Molassiotis A, Russell W, Hughes J, et al. The effectiveness and cost-effectiveness of acupressure for the control and management of chemotherapy-related acute and delayed nausea: Assessment of Nausea in Chemotherapy Research (ANCHoR), a randomisedcontrolled trial. Health Technology Assessment. 2013; 17(26): 1-114. PMid:23803562 http://dx.doi.org/10.3310/hta17260

[20] Dibble SL, Chapman J, Mack KA, et al. Acupressure for nausea: results of a pilot study. Oncol Nurs Forum. 2010; 27(1): 41-7.

[21] Garrett K, Tsuruta CK, Walker AS, et al. Managing nausea and vomiting. Current Strategies. Crit Care Nurse. 2011; 23(1): 31-50.
[22] Lee J, Dibble S, Dodd M, et al. The relationship of chemotherapyinduced nausea to the frequency of pericardium 6 digital acupressure. Oncology Nursing Forum. 2010; 37: 419-425. PMid:21059575 http://dx.doi.org/10.1188/10.0NF.E419-E425

[23] Shin YH, Kim T, Shin MS, et al. Effect of acupressure on nausea and vomiting during chemotherapy cycle for Korean postoperative stomach cancer patients. Cancer Nurs. 2011; 27(4): 267-74 http://dx.doi.org/10.1097/00002820-200407000-00002

[24] Anthony SJ, Selkirk E, Sung L, et al. Considering quality of life for adolescents with cancer: A systematic review of patient-reported outcome measures and the development of a conceptual model. Quality of Life Research. 2014; 23: 771-789. PMid:23907613 http://dx.doi.org/10.1007/s11136-013-0482-x

[25] Augusto F, Luisi V, Petrilli AS, et al. Contribution to the treatment of nausea and emesis induced by chemotherapy in adolescents and adolescents with osteosarcoma. Sao Paulo Med J. 2010; 124(2): 61-5.

[26] Abd El-Moneem DSE. Effect of acupressure on chemotherapy induced nausea and vomiting among cancer patient. Thesis submitted for partial fulfillment of the Doctorate in Nursing Science, Degree, Medical-Surgical Nursing, Faculty of Nursing, Cairo University, 2010.

[27] Taspinar A, Sirin A. Effect of acupressure on chemotherapy induced nausea and vomiting in gynecologic cancer patients in Turkey. European J Oncology Nursing. 2010; 14(1): 49-54. PMid:19748316 http://dx.doi.org/10.1016/j.ejon.2009.07.006

[28] Wulffa B, Schmidta C, Lehmannb N, et al. Pericardium 6 acupressure and acupuncture as additive antiemetic therapy during chemotherapy in adolescents and adolescents-A randomized placebocontrolled pilot study. Eur J Med. 2009; 1(4): 205-206. http: //dx.doi.org/10.1016/j.eujim. 2009.08.122

[29] Gottschling S, Reindl TK, Meyer S, et al. Acupressure to alleviate chemotherapy-induced nausea and vomiting in pediatric oncology a randomized multi center crossover pilot trial. Klin Padiatr. 2009; 220(6): 365-370. PMid:18949672 http://dx . doi .org/10.1055 /s-0028-1086039

[30] Özkan A, Yildiz I, Yüksel L, et al. Tropisetron (Navoban) in the Control of Nausea and Vomiting Induced by Combined Cancer Chemotherapy in Adolescents. Jpn J Clin Oncol. 2010; 29(2): 92-95. http://dx.doi.org/10.1093/jjco/29.2.92

[31] Genc F, Tan M. The effect of acupressure application on chemotherapy-induced nausea, vomiting, and anxiety in patients with breast cancer. Palliative \& Supportive Care. 2014. 